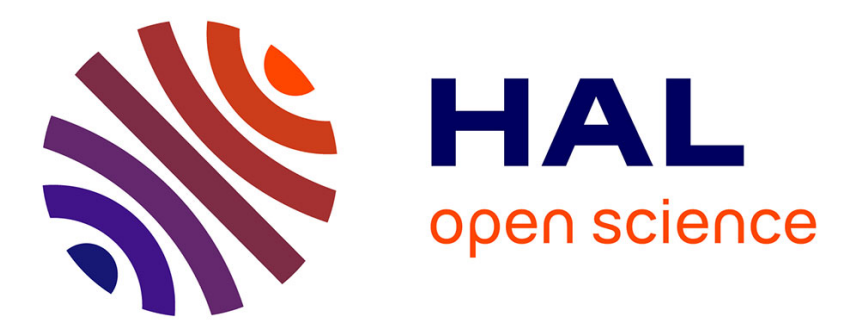

\title{
Gold(I)-Catalyzed Intramolecular Hydroamination and Hydroalkoxylation of Alkynes: Access to Original Heterospirocycles
}

Kossi Efouako Soklou, Hamid Marzag, Jean-Philippe Bouillon, Mathieu Marchivie, Sylvain Routier, Karen Plé

\section{To cite this version:}

Kossi Efouako Soklou, Hamid Marzag, Jean-Philippe Bouillon, Mathieu Marchivie, Sylvain Routier, et al.. Gold(I)-Catalyzed Intramolecular Hydroamination and Hydroalkoxylation of Alkynes: Access to Original Heterospirocycles. Organic Letters, 2020, 22 (15), pp.5973-5977. 10.1021/acs.orglett.0c02070 . hal-02916186

\section{HAL Id: hal-02916186 https://hal.science/hal-02916186}

Submitted on 26 Aug 2020

HAL is a multi-disciplinary open access archive for the deposit and dissemination of scientific research documents, whether they are published or not. The documents may come from teaching and research institutions in France or abroad, or from public or private research centers.
L'archive ouverte pluridisciplinaire HAL, est destinée au dépôt et à la diffusion de documents scientifiques de niveau recherche, publiés ou non, émanant des établissements d'enseignement et de recherche français ou étrangers, des laboratoires publics ou privés. 


\title{
Gold (I)-catalyzed intramolecular hydroamination and hydroalkoxylation of alkynes : access to original heterospirocycles
}

\author{
Kossi Efouako Soklou ${ }^{1 \ddagger}$, Hamid Marzag ${ }^{1 \ddagger}$, Jean-Philippe Bouillon², Mathieu Marchivie ${ }^{3}$, Sylvain Rou- \\ tier $^{1 *}$, and Karen Plé ${ }^{1 *}$
}

1. Institut de Chimie Organique et Analytique, Université d'Orléans, CNRS UMR 7311, 45067 Cedex 2 Orléans, France.

2. Normandie Université, COBRA, CNRS UMR 6014, Université de Rouen, 76000 Rouen, France.

3. Université de Bordeaux, ICMCB CNRS-UMR 5026, 33608 Pessac, France.

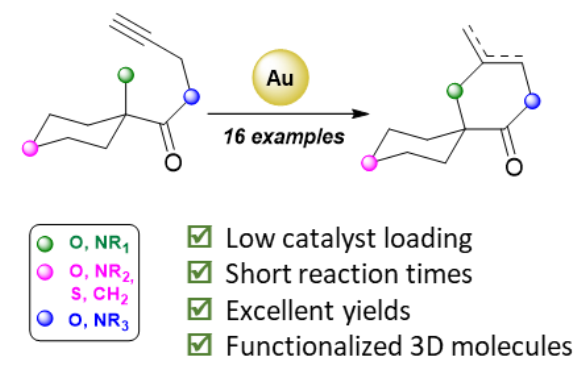

ABSTRACT: We report here a simple and robust gold-catalyzed annulation reaction, giving $N$ - and $O$-spirocycles in good to excellent yields. We have prepared a library of protected amines and tertiary alcohols which give, upon cyclization with alkynes, a representative set of heterospirocycles, and illustrate reaction compatibility with diverse functional groups. A change in catalytic activity is possible by modifying the solvent, and two original tricyclic spirocycles were synthesized in a tandem reaction.

Spirocycles are characterized by the presence of a fully substituted $\mathrm{sp}^{3}$ carbon which defines a well-organized 3D orthogonal structure. They are attractive targets in the search for chemical diversity, and as an escape from "flatland" in medicinal chemistry. ${ }^{1-5}$ Different synthetic methodologies have been developed to generate these scaffolds, but their preparation remains challenging. ${ }^{6-11}$ There are several common strategies available to construct the spirocyclic core, ${ }^{12}$ and metal catalysis is one important option. The use of organometallic reagents generally avoids aggressive reaction conditions, reduces the risk of side reactions, and can remove certain reaction barriers while maintaining compatibility with most organic functions.

Gold catalysis has been widely used for the construction of carbon-carbon or carbon-heteroatom bonds over the past 15 years. ${ }^{13-17}$ The gold-catalyzed activation of alkynes followed by inter- or intramolecular nucleophilic attack leads to a multitude of different chemical structures. ${ }^{18,19}$ In particular, gold (I)-catalyzed hydroamination and hydroalkoxylation are both powerful methods for building new heterocycles. ${ }^{20-22}$ Gold catalysis has changed the way chemists view reactivity and bond formation, giving access to a greater number of available nucleophilic partners, even those that are traditionally seen as non-nucleophilic.

In general, when a heteroatom is attached to a fully substituted carbon center, its reactivity is limited because of the hindered steric environment. Harsh conditions are often necessary for the heteroatom to engage in further reactions, particularly during ring formation to create a new spirocyclic center. To overcome this problem, we sought to develop a mild and efficient process which would both boost reactivity and promote intramolecular cyclization to form new functionalized heterospirocycles starting from tertiary alcohols and the corresponding protected amines. Although gold catalysis has been effectively used for spiroacetal formation, ${ }^{23}$ reports of intramolecular gold-catalyzed ring formation with amines or alcohols attached to a fully substituted carbon center remain scarce when compared to their less hindered counterparts. ${ }^{24-28}$ Literature examples are, in most cases, reserved to specific substrates with no further exploration.

As illustrated in Scheme 1 [a-c], formal hydroxyalkoxylation or hydroamination reactions with alkynes have been described with both gold (I) or (III) catalysts, but hydration or further oxidation is always observed, either by capture of the reactive intermediate or as a desired part of the reaction process. ${ }^{29-31}$ In our work, the addition of various tertiary alcohols or protected amines to alkynes has been achieved without affecting the oxidation state of the newly formed spirocycle (Scheme $1[\mathrm{~d}]$ ). 
Scheme 1. Gold-catalyzed heterospirocyclization in the literature [a-c]. Our proposed methodology [d].

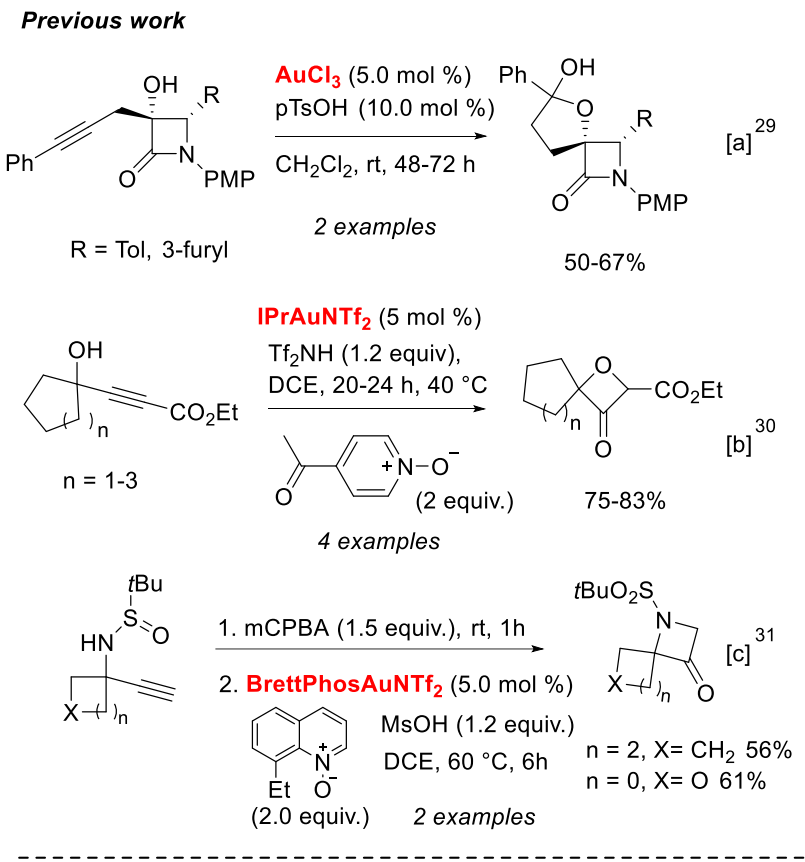

This work

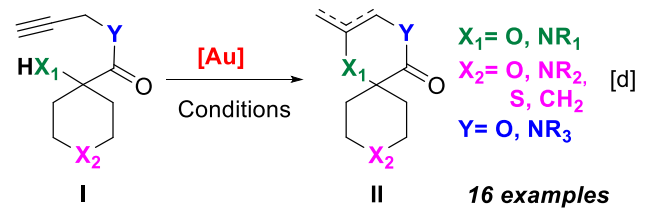

We wish to report here the gold-catalyzed intramolecular hydroamination and hydroalkoxylation of alkynes with tertiary alcohols or protected amines to form new spirocycles. Starting from the general structure I containing either a piperidine, a tetrahydro(thio)pyran ring or a simple carbocyle, access to dihydro- pyrazinone and oxazinone spirocycles with the general structure II was achieved (Scheme $1[\mathrm{~d}]$ ).

Initial tests were carried out using the commercially available 4-N-Boc-amino-1-Cbz-piperidine-4-carboxylic acid functionalized with propargylamine. JohnPhosAu(MeCN)SbF 6 was chosen as catalyst because acetonitrile is a relatively weak coordinating ligand and is easily displaced, thus avoiding the use of addition silver salts to activate the catalytic species. To our disappointment, heating the secondary amide $\mathbf{1}$ in the presence of the gold complex gave the oxazoline derivative $\mathbf{2}$ in good yield (Scheme 2). ${ }^{32}$ Using different gold catalysts such as $\left(\mathrm{Ph}_{3} \mathrm{P}\right) \mathrm{AuCl}$ or JohnPhosAuCl gave the same results.

\section{Scheme 2. Oxazoline formation}

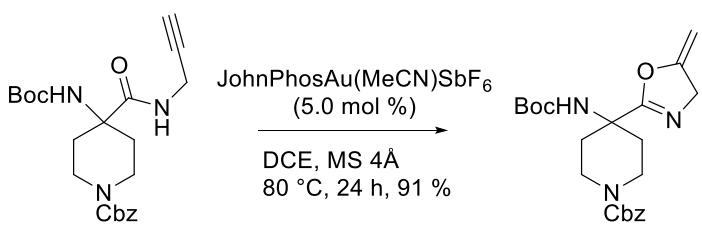

2

To avoid oxazoline formation due to tautomerization of the secondary amide, the corresponding $N$-methyl amide 3 was prepared. Conventional heating $\left(80^{\circ} \mathrm{C}\right)$ in the presence of $5.0 \mathrm{~mol} \%$ of JohnPhosAu(MeCN)SbF 6 gave an $81 \%$ yield of the endocyclic product 5. The presence of the exocyclic compound 4 was undetected. (Table 1, entry 1). Even though 
our first reaction was successful, we felt that there was room for improvement, so we set out to optimize various reaction conditions such as reaction length, catalyst and loading (see SI for catalyst structures).

Table 1. Optimization of Au-catalyzed cyclization and catalyst screening.

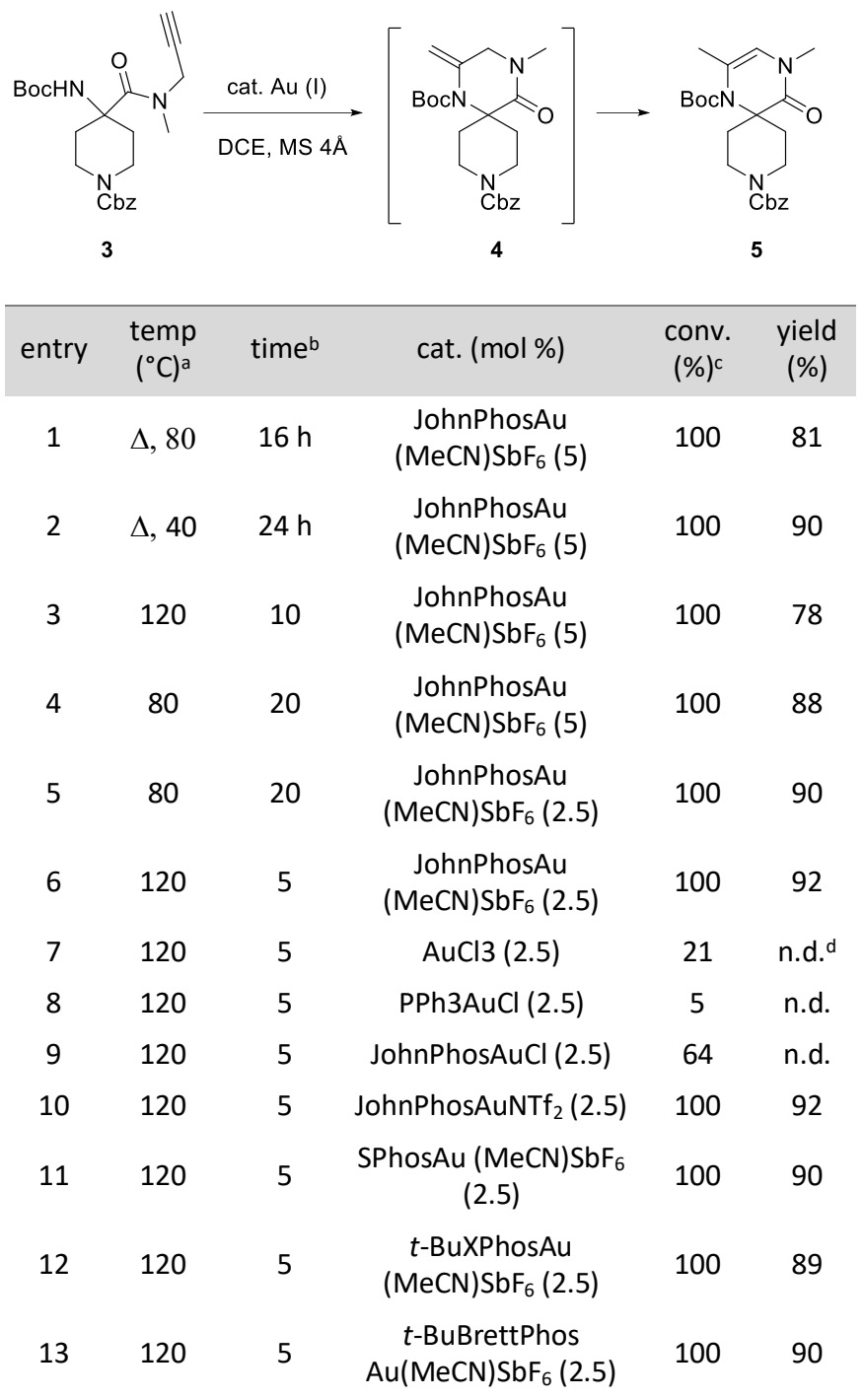

${ }^{\mathrm{a}} \mu \mathrm{W}$ irradiation unless otherwise indicated. ${ }^{\mathrm{b}}$ Time in minutes unless otherwise indicated. ${ }^{\mathrm{c}}$ Determined by ${ }^{1} \mathrm{H}$ NMR analysis. ${ }^{\mathrm{d}} \mathrm{n} . \mathrm{d} .=\mathrm{not}$ determined.

A slight increase in yield was obtained by lowering the reaction temperature to $40{ }^{\circ} \mathrm{C}$ (entry 2 ), but $24 \mathrm{~h}$ were necessary for full conversion of the starting material. Microwave irradiation was then tested to shorten the reaction time, with spectacular results. Only 10 minutes at $120^{\circ} \mathrm{C}$ were necessary to obtain $78 \%$ of the desired spirocycle (entry 3 ). Lowering the reaction temperature, but for a longer period of time, gave the desired product in $88 \%$ yield (entry 4). Decreasing the catalyst loading to $2.5 \mathrm{~mol} \%$ was possible with no effect on the reaction efficiency (entry 5). Finally, the best results were obtained with a $2.5 \mathrm{~mol} \%$ catalyst loading at $120^{\circ} \mathrm{C}$ for only 5 minutes under microwave irradiation (entry 6). Different gold chloride catalysts were then tested but substrate conversion was poor in all cases (entries 7-9). In comparison, the presence of the weakly coordinating bis(trifluoromethanesulfonyl)amide ligand (entry 10) gave the desired product in excellent yield, confirming our results in which highly coordinating anions are poorly reactive (entries 9 vs 10). The nature of the phosphine ligand was then modified (entries 11-13) with no significant difference in reactivity. We thus chose JohnPhosAu(MeCN)SbF 6 as the best catalyst with regard to both cost and availability. The potentially 
deactivating tert-butyloxycarbonyl (Boc) amino protecting group had no effect on cyclization, and the presence of intermediate $\mathbf{4}$ was never observed in any of the reactions.

We then applied the optimized conditions to the corresponding oxygenated substrate 7, made in 4 steps and $58 \%$ yield from commercially available 1-(benzyloxycarbonyl)-4-piperidinone (see SI for the detailed synthesis of 7).

\section{Scheme 3. Spirocyclization with a tertiary hydroxyl group.}

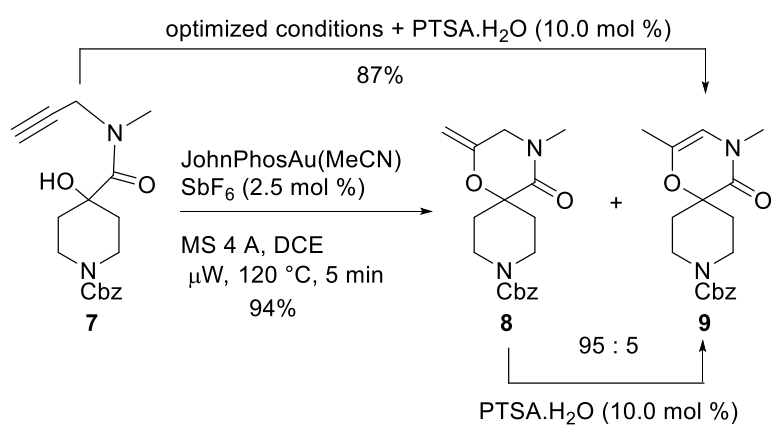

In this case, the formation of two alkene regioisomers was observed in $94 \%$ overall yield as a clean mixture with no need for purification (Scheme 3). We were surprised to find that the major reaction product was the exomethylene derivative 8 , as determined by ${ }^{1} \mathrm{H}$ NMR. Separation of the isomers by column chromatography gave a $74 \%$ isolated yield of 8 , the remaining amount being a mixture of the two compounds. A shorter reaction time ( 1 or 2 min) was ineffective in suppressing the small amount of isomerized product $\mathbf{9}$ formed. Moreover, we also found that compound $\mathbf{8}$ was easily transformed into 9 when treated with $p$-toluenesulfonic acid (PTSA. $\left.\mathrm{H}_{2} \mathrm{O}\right)(10.0 \mathrm{~mol} \%)$ at rt (total conversion after 5 $\mathrm{min}$ ). This led us to perform the reaction in the presence of PTSA to provoke double bond migration in situ, giving the endo isomer 9 as the unique product in $87 \%$ isolated yield.

To evaluate the observed microwave effect, compound $\mathbf{7}$ was subjected to our optimized conditions in a sealed tube at $120^{\circ} \mathrm{C}$ in a preheated heating block. Conventional heating was less efficient with only a $78 \%$ conversion and a $55 \%$ isolated yield.

Crystallization of the regioisomer 9 gave us the opportunity to prove its structure by X-ray analysis. The ORTEP representation (Figure 1) clearly shows an oxazinone moiety linked by a fully substituted carbon to a piperidine moiety in chair conformation with the oxygen atom in the axial position. The oxazinone ring is not planar due to a significant deviation from the mean plane of the $\mathrm{C} 4$ and $\mathrm{O} 3$ atoms.

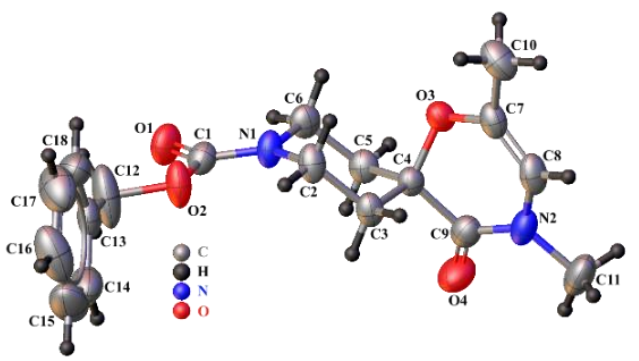

Figure 1. ORTEP representation of compound 9.

With these results in hand, we wished to generalize this quick and efficient gold-catalyzed spirocyclization to other nitrogen and oxygen containing substrates of type I (see SI for preparation of the starting amides 10-22). A catalytic amount of PTSA. $\mathrm{H}_{2} \mathrm{O}$ was systematically added in the oxygen series to favor double bond migration and give only one product.

The desired $\mathrm{N}$-spirocycles were obtained in good to excellent yields (Figure 2). The use of $\mathrm{N}$-Boc protected substrates gave the corresponding endocyclic double bonds in all cases whereas protection with a $p$-toluenesulfonyl group led to 
the exclusive formation of an exocyclic double bond (29). For this substrate, a reduced reactivity was also observed, as microwave irradiation for 2 hours was necessary for a complete conversion with a total of 5\% mol JohnPho$\mathrm{sAu}\left(\mathrm{MeCN}_{\mathrm{SbF}} \mathrm{Sb}_{6}\right.$. This lack of reactivity can most likely be explained by the electron withdrawing nature of the amino protecting group (Tosyl vs Boc). Heterospirocyclization was compatible with the presence of sulfur atoms, although with a substantially longer reaction time of $2.5 \mathrm{~h}$ to give the desired product $\mathbf{2 5}$ in $\mathbf{7 9 \%}$ yield. A slight decrease in yield was also observed when the starting substrates contained multiple bonds (final compounds $\mathbf{2 6}$ and 27).

We performed the cyclization with amide 3 on a $1.0 \mathrm{mmol}$ scale using our optimized conditions. For practical purposes, linked to the use of microwave irradiation and the limit imposed by the size of the microreactors, it was carried out at a concentration of $0.08 \mathrm{M}$. To our satisfaction, the spirocycle 5 was obtained in an excellent $98 \%$ yield. In a second larger scale reaction $(2.6 \mathrm{mmol})$, increasing the reaction concentration to $0.26 \mathrm{M}$ was successfully achieved, while simultaneously lowering the catalyst loading to only $1.0 \mathrm{~mol} \%$. Once again, we observed no changes in outcome or yield $(96 \%)$. One real advantage of our process is that microwave irradiation is only 5 minutes on whatever scale performed for the majority of our substrates. Cyclization is also independent of reaction concentration, and no intermolecular side reactions occur.

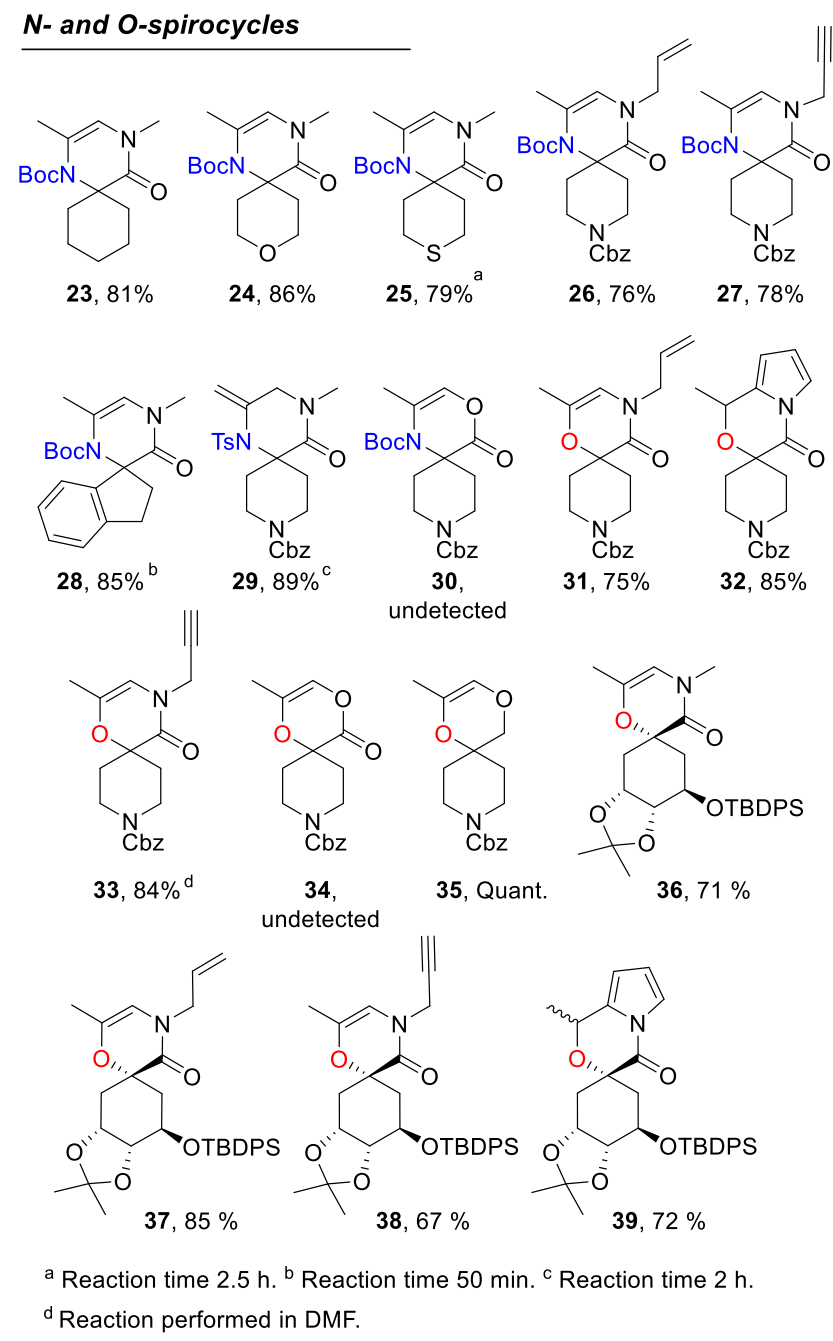

Figure 2 : Substrate scope of the heterospirocyclization reaction. 
Extending the scope of the reaction in the oxygen series gave the $N$-allyl derivative (31) in moderate yield (Figure 2). Use of a di-propargyl substituted amide led to a unique tricyclic structure, which was obtained in good yield through a double in situ cyclization process (32). The corresponding endo precursor (33) could be prepared by performing the reaction in DMF, which presumably reduces catalytic efficiency by complexation of the gold catalyst. One limitation that we found in both series was the absence of cyclization when an ester was present in the starting material (30 and 34). Surprisingly, the unreacted esters were fully recovered in both cases. This constraint was lifted with the removal of the carbonyl group, and the use of a simple ether, which gave compound $\mathbf{3 5}$ quantitatively.

We then decided to apply the spirocyclization reaction to a more complex chiral substrate. Several amide derivatives were prepared from a protected quinic acid derivative in good yields (see SI for preparation of starting compounds). Cyclization was performed in the presence of a catalytic amount of PTSA. $\mathrm{H}_{2} \mathrm{O}$ in all cases to give the corresponding spirocycles 36-39. No racemization of the chiral quaternary stereocenter was observed $\left({ }^{1} \mathrm{H} N \mathrm{NR}\right)$, and the tricyclic product $\mathbf{3 9}$ was obtained as a separable mixture of diastereomers.

Our next steps were devoted to further transforming our molecules through selective deprotection of the amino groups and/or double bond reduction. Hydrogenation of compound $\mathbf{5}$ in the presence of palladium chloride allowed the removal of the benzyl carbamate in $70 \%$ yield, with no observed reduction of the double bond (Scheme 4). Conventional alkene reduction methods $\left(\mathrm{H}_{2}, \mathrm{Pd} / \mathrm{C}\right.$ or Pt) were unsuccessful, with recovery of the unreacted starting material. Ionic conditions were then tried, and while the use of triethylsilane/trifluoroacetic acid failed with compound $\mathbf{5}$, they proved to be successful starting from spirocycle $9 .^{33}$ The desired spiromorpholinone $\mathbf{4 1}$ was isolated in $\mathbf{8 4 \%}$ yield.

\section{Scheme 4. Protecting group removal and double bond reduction.}

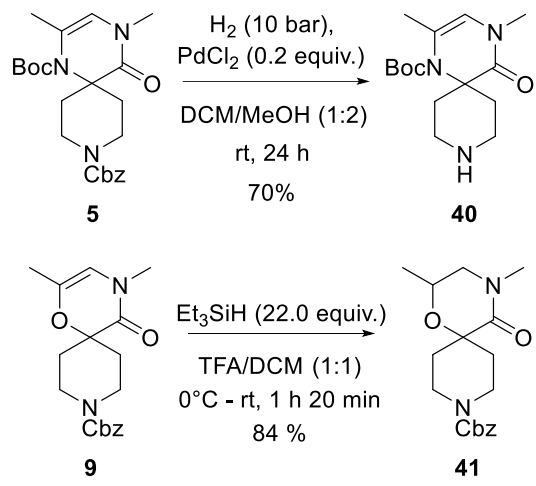

In conclusion, we have developed a spirocyclization reaction based on the intramolecular gold-catalyzed hydroamination and hydroalkoxylation of alkynes. Both tertiary alcohols and protected amines react to form new heterospirocycles in good to excellent yields under microwave irradiation in only a few minutes with low catalyst loading. We prepared a small library of spirocycles containing dihydro- pyrazinone and oxazinone cores, with no further oxidation of the final product. Gram quantities were also prepared in a practical and robust manner with an even lower catalyst loading. We have likewise proven the compatibility of the method toward asymmetric centers as well as common protective groups. As an added bonus, a tandem reaction to give unique tricyclic spirocycles ( 32 and $\mathbf{3 9}$ ) was observed, and catalyst reactivity could be altered using DMF as a coordinating solvent. Further reactions such as isomerization, reduction, and selective deprotection increase the significance of the present work, and offer possibilities for the use of these spirocyles as candidates to increase molecular diversity in medicinal chemistry.

\section{ASSOCIATED CONTENT}

Supporting Information.

The Supporting Information is available free of charge on the ACS Publications website.

Experimental procedures, ${ }^{1} \mathrm{H}$ NMR and ${ }^{13} \mathrm{C}$ NMR for 
all compounds (PDF)

Crystallographic Information File for 9 (CIF)

\section{AUTHOR INFORMATION}

\section{Corresponding Author}

*E-mail: karen.ple@univ-orleans.fr

\section{Author Contributions}

¥These authors contributed equally.

\section{ACKNOWLEDGMENT}

The authors would like to thank the Région Centre Val de Loire (PhD funding SKE), the Labex programs SYNORG (ANR-11-LABX-0029) and IRON (ANR-11-LABX-0018-01), the Ligue contre le Cancer du Grand Ouest (comités des Deux Sèvres, du Finistère, de l'lle et Villaine, du Loir et Cher, de Loire Atlantique, du Loiret, de la Vienne), and the Canceropole Grand Ouest for their financial support.

\section{REFERENCES}

(1) Kirichok, A. A.; Shton, I. O.; Pishel, I. M.; Zozulya, S. A.; Borysko, P. O.; Kubyshkin, V.; Zaporozhets, O. A.; Tolmachev, A. A.; Mykhailiuk, P. K., Synthesis of Multifunctional Spirocyclic Azetidines and Their Application in Drug Discovery. Chem. Eur. J. 2018, 24, 5444-5449.

(2) Geary, G. C.; Nortcliffe, A.; Pearce, C. A.; Hamza, D.; Jones, G.; Moody, C. J., Densely functionalised spirocyclic oxet ane-piperidine scaffolds for drug discovery. Bioorg. Med. Chem. 2018, 26, 791-797.

(3) Müller, G.; Berkenbosch, T.; Benningshof, J. C. J.; Stumpfe, D.; Bajorath, J., Charting Biologically Relevant Spirocyclic Compound Space. Chem. Eur. J. 2017, 23, 703-710.

(4) Kumar, S.; Thornton, P. D.; Painter, T. O.; Jain, P.; Downard, J.; Douglas, J. T.; Santini, C., Synthesis of a Family of Spirocyclic Scaffolds: Building Blocks for the Exploration of Chemical Space. J. Org. Chem. 2013, 78, 6529-6539.

(5) Kang, F.-A.; Sui, Z., A diversity-oriented-synthesis protocol for scaffold discovery based on a general synthetic route to spirocycles. Tetrahedron Lett. 2011, 52, 4204-4206.

(6) Kotha, S.; Ali, R.; Chinnam, A. K., Diversity-oriented approach to spirocycles via ring-closing metathesis. Tetrahedron Lett. 2014, 55, 4492-4495.

(7) Carreira, E. M.; Fessard, T. C., Four-Membered Ring-Containing Spirocycles: Synthetic Strategies and Opportunities. Chem. Rev. 2014, 114, 82578322.

(8) D'yakonov, V. A.; Trapeznikova, O. A.; de Meijere, A.; Dzhemilev, U. M., Metal Complex Catalysis in the Synthesis of Spirocarbocycles. Chem. Rev. 2014, 114, 5775-5814.

(9) Siau, W.-Y.; Bode, J. W., One-Step Synthesis of Saturated Spirocyclic N-Heterocycles with Stannyl Amine Protocol (SnAP) Reagents and Ketones. J. Am. Chem. Soc. 2014, 136, 17726-17729.

(10) Stotani, S.; Lorenz, C.; Winkler, M.; Medda, F.; Picazo, E.; Ortega Martinez, R.; Karawajczyk, A.; Sanchez-Quesada, J.; Giordanetto, F., Design and Synthesis of Fsp3-Rich, Bis-Spirocyclic-Based Compound Libraries for Biological Screening. ACS Comb. Sci. 2016, 18, 330-336.

(11) Kotha, S.; Panguluri, N. R.; Ali, R., Design and Synthesis of Spirocycles. Eur. J. Org. Chem. 2017, 5316-5342.

(12) Ding, A.; Meazza, M.; Guo, H.; Yang, J. W.; Rios, R., New development in the enantioselective synthesis of spiro compou nds. Chem. Soc. Rev. 2018, 47, 5946-5996.

(13) Li, Z.; Brouwer, C.; He, C., Gold-Catalyzed Organic Transformations. Chem. Rev. 2008, 108, 3239-3265.

(14) Toste, F. D., Gold catalysis for organic synthesis. Beilstein J. Org. Chem. (Thematic edition) 2011, 7, 553-554.

(15) Toste, F. D., Gold catalysis for organic synthesis II. Beilstein J. Org. Chem. (Thematic edition) 2013, 9, 2040-2041.

(16) Friend, C. M.; Hashmi, A. S. K., Gold Catalysis (Special thematic edition on gold catalysis). Acc. Chem. Res. 2014, 47, 729-730.

(17) Rudolph, M.; Hashmi, A. S. K., Heterocycles from gold catalysis. Chem. Commun. 2011, 47, 6536-6544.

(18) Dorel, R.; Echavarren, A. M., Gold(I)-Catalyzed Activation of Alkynes for the Construction of Molecular Complexity. Chem. Rev. 2015, 115, 90289072.

(19) Alyabyev, S. B.; Beletskaya, I. P., Gold as a catalyst. Part I. Nucleophilic addition to the triple bond. Russ. Chem. Rev. 2017, 86, 689-749.

(20) Alcaide, B.; Almendros, P., Gold-Catalyzed Cyclization Reactions of Allenol and Alkynol Derivatives. Acc. Chem. Res. 2014, 47, 939-952.

(21) Alcaide, B.; Almendros, P.; Alonso, J. M., Gold catalyzed oxycyclizations of alkynols and alkyndiols. Org. Biomol. Chem. 2011, 9, 4405-4416.

(22) Arcadi, A., Gold-Catalyzed Synthesis of Nitrogen Heterocyclic Compounds via Hydroamination Reactions. In Au-Catalyzed Synthesis and Functionalization of Heterocycles, Bandini, M., Ed. Springer International Publishing, 2016, 53-85.

(23) Wagner, B.; Belger, K.; Minkler, S.; Belting, V.; Krause, N., Sustainable gold catalysis: synthesis of new spiroacetals. Pure Appl. Chem. 2016, 88, 391-399.

(24) Yu, Y.-F.; Shu, C.; Zhou, B.; Li, J.-Q.; Zhou, J.-M.; Ye, L.-W., Efficient and practical synthesis of enantioenriched 2,3-dihydropyrroles through goldcatalyzed anti-Markovnikov hydroamination of chiral homopropargyl sulfonamides. Chem. Commun. 2015, 51, 2126-2129.

(25) Alcaide, B.; Almendros, P., Gold-catalyzed heterocyclizations in alkynyl- and allenyl- $\beta$-lactams. Beilstein J. Org. Chem. 2011, 7, 622-630.

(26) Egi, M.; Azechi, K.; Saneto, M.; Shimizu, K.; Akai, S., Cationic Gold(I)-Catalyzed Intramolecular Cyclization of $\gamma$-Hydroxyalkynones into 3(2H)Furanones. J. Org. Chem. 2010, 75, 2123-2126.

(27) Liu, Y.; Song, F.; Song, Z.; Liu, M.; Yan, B., Gold-Catalyzed Cyclization of (Z)-2-En-4-yn-1-ols: Highly Efficient Synthesis of Fully Substituted Dihydrofurans and Furans. Org. Lett. 2005, 7, 5409-5412. 
(28) Barluenga, J.; Fernández, A.; Diéguez, A.; Rodríguez, F.; Fañanás, F. J., Gold- or Platinum-Catalyzed Cascade Processes of Alkynol Derivatives Involving Hydroalkoxylation Reactions Followed by Prins-Type Cyclizations. Chem. Eur. J. 2009, 15, 11660-11667.

(29) Alcaide, B.; Almendros, P.; Martínez del Campo, T.; Carrascosa, R., Metal-Catalyzed Cycloisomerization and Tandem Oxycyclization/Hydroxylation of Alkynols: Synthesis of Nonfused, Spiranic and Fused Oxabicyclic $\beta$-Lactams. Eur. J. Org. Chem. 2010, 4912-4919.

(30) Ye, L.; He, W.; Zhang, L., Gold-Catalyzed One-Step Practical Synthesis of Oxetan-3-ones from Readily Available Propargylic Alcohols. J. Am. Chem. Soc. 2010, 132, 8550-8551.

(31) Ye, L.; He, W.; Zhang, L., A Flexible and Stereoselective Synthesis of Azetidin-3-ones through Gold-Catalyzed Intermolecular Oxidation of Alkynes. Angew. Chem. Int. Ed. 2011, 50, 3236-3239.

(32) Weyrauch, J. P.; Hashmi, A. S. K.; Schuster, A.; Hengst, T.; Schetter, S.; Littmann, A.; Rudolph, M.; Hamzic, M.; Visus, J.; Rominger, F.; Frey, W.; Bats, J. W., Cyclization of Propargylic Amides: Mild Access to Oxazole Derivatives. Chem. Eur. J. 2010, 16, 956-963.

(33) Wang, Y.; Zhang, W.-Y.; You, S.-L., Ketones and Aldehydes as O-Nucleophiles in Iridium-Catalyzed Intramolecular Asymmetric Allylic Substitution Reaction. J. Am. Chem. Soc. 2019, 141, 2228-2232. 
For Table of Contents only.

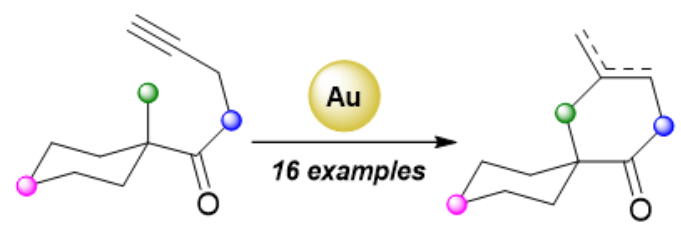

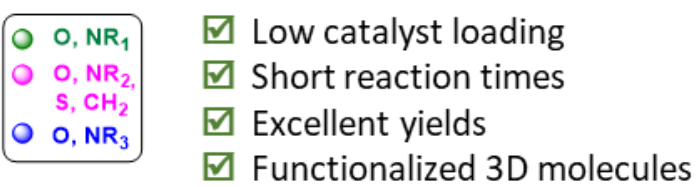

